\title{
ANALISIS STRUKTURALISME TEKS DRAMA JAKA TARUB DAN 7 BIDADARI KARYA AKHUDIAT
}

\author{
Nurul Utami \\ Universitas Muhammadiyah Jakarta \\ nurulut@gmail.com
}

\begin{abstract}
ABSTRAK
Penelitian ini bertujuan untuk mendeskripsikan dari unsur tokoh, peran, karakter peristiwa, alur maupun latar, penggarapan Bahasa, dan amanat yang terdapat pada naskah drama Jaka Tarub dan 7 Bidadari, untuk jenis penelitian ini ialah kualitatif dengan metode deskriptif. Hasil penelitian menunjukan bahwa naskah drama ini memiliki empat belas tokoh simbolis dengan karakternya masing-masing. Berikut motif dalam naskah drama ini yaitu hilangnya selendang Nawang Wulan salah satu bidadari dari kahyangan yang datang ke mayapada (Bumi) untuk mandi di danau bersama bidadari yang lainnya dan yang tak lain dan tak bukan Jaka Tarub sendiri lah yang menyembunyikan salah satu selendang bidadari itu secara diam-diam tanpa sepengetahuan siapa pun itu. Lalu konfliknya yaitu terjadinya persaingan balas dendam antara Raja Bintara dengan Raja Ajisaka di kahyangan. Dan adapun amanat yang dapat di ambil yaitu: jangan merebut hak orang lain karena itu perbuatan yang tidak baik.
\end{abstract}

Kata Kunci: karakter, konflik, amanat

ABSTRACT
This study aims to describe the elements of characters, roles, character of events, plot and setting, language cultivation, and the mandate contained in the drama script Jaka Tarub and 7 Angels, for this type of research is qualitative with descriptive methods. The results showed that this drama script had fourteen symbolic characters with their respective characters. The following motive in this drama script is the loss of the Nawang Wulan shawl, one of the nymphs from heaven who came to Mayapada (Earth) to bathe in the lake with other nymphs and none other than Jaka Tarub himself who hid one of the angel shawls. quietly without anyone's knowledge. Then the conflict is the occurrence of revenge competition between King Bintara and King Ajisaka in heaven. And as for the mandate that can be taken namely: do not seize the rights of others because it is not good deeds.

Keywords: character, conflict, mandate 
berkaitan, dan saling menentukan satu sama lain (Eryanti, Rahman, dan Permana, 2015). Unsur-unsur tersebut adalah unsur intrinsik dan unsur ekstrinsik. Unsur intrinsik adalah unsur yang membangun karya sastra dari dalam atau karya itu sendiri (Weisberg dan Goodstein, 2009), sedangkan unsur ekstrinsik adalah unsur yang membangun karya sastra dari luar (Kemal, 2013).

Analisis pendekatan strukturalisme ini betujuan untuk membongkar dan memaparkan sercermat, seteliti, semenditel, dan semendalam mngkin keterkaitan dan keterjalinan semua analisis dan aspek karya sastra yang bersama-sama menghasilkan makna menyeluruh. Dalam pandangan saussure kata-kata bukan simmbolsimbol yang berhubungan dengan rujukan atau (referen), tapi lebih merupakan "tanda" yang terbangun dari dua bagian: tanda, baik yang tertulis maupun di ucapkan, di sebut "penanda" dan konsep (apa yang "dipikirkan" ketika tanda di buat), di sebut "petanda" ("yang ditandai").

Drama berasal dari kata Yunani, draomi yang berarti berbuat, bertindak, bereaksi, dan sebagainya. Drama mempunyai dua arti, yaitu drama dalam arti luas dan drama dalam arti sempit. Drama dalam arti luas adalah semua bentuk tontonan yang mengandung cerita yang dipertunjukkan di depan orang banyak. Dalam arti sempit, pengertian drama adalah kisah hidup manusia yang diproyeksikan ke atas panggung. Drama adalah karya sastra yang bertujuan menggambarkan kehidupan dengan mengemukakan tikaian dan emosi lewat lakuan dan dialog (Gemtou, 2014).

Dan drama pun sebagai salah satu genre sastra juga dibangun oleh sebuah struktur. Selain dari itu drama juga memiliki karakteristik khusus yaitu berupa dialog. Semua peristiwa dan konflik yang terjadi dipaparkan dan dibeberkan melalui dialog. Drama ditulis dalam bentuk dialog dengan tujuan untuk dipentaskan sebagai suatu seni pertunjukan. Oleh karena itu drama disebut karya sastra dua dimensi yaitu dimensi sastra dan dimensi pertunjukan. Sebagai karya dua dimensi, drama dalam dimensi sastralah yang pengkajiannya terkait dengan struktur.

Drama dikelompokkan sebagai karya sastra karena menggunakan media bahasa (Tsai, Chang, dan Huang, 2016). Sebagai salah satu genre sastra, drama dibangun oleh unsur intrinsik dan ekstrinsik. Unsur intrinsik drama, meliputi: 1) tokoh, peran, dan karakter; 2) motif, peristiwa, konflik, dan alur; 3) latar dan ruang; 4) penggunaan bahasa; 5) tema dan amanat (Hasanuddin W.S., 1996). Tokoh merujuk pada orang atau pelaku cerita, sedangkan watak dan karakter merujuk pada sifat dan sikap para tokoh dan lebih merujuk pada kualitas pribadi seorang tokoh (Nurgiyantoro, 1994: 165). Konflik adalah sesuatu dramatik, mengacu pada pertarungan antara dua kekuatan yang seimbang dan menyiratkan adanya aksi dan aksi balasan 


\section{METODE}

Metode yang digunakan adalah metode yang bersifat deskriptif dan cenderung menggunakan analisis. Data penelitian ini adalah berupa kata-kata, kalimat dan dialog yang terdapat dalam naskah drama. Selanjutnya dianalisis berdasarkan teori menurut Hasanuddin WS yang telah dipaparkan dalam uraian di atas. Tahap analisis yang dilakukan dalam penelitian ini dengan cara sebagai berikut: (1) mendeskripsikan data yang berhubungan dengan struktural naskah drama Jaka Tarub dan 7 Bidadari karya akhudiat, (2) mengidentifikasi data sesuai dengan struktur naskah drama Jaka Tarub dan 7 Bidadari, (3) menginventarisasi struktur naskah drama Jaka Tarub dan 7 Bidadari, (4) membuat kesimpulan berdasarkan hasil penelitian, (5) melaporkan hasil penelitian. Teknik pengabsahan data yang digunakan adalah teknik uraian rinci.

PEMBAHASAN tarub dan 7 Bidadari karya akhudiat di temukan unsur-unsur yang membangun naskah drama yang meliputi: unsur tokoh, peran, karakter, motif, konflik, peristiwa, alur, penggunaan bahasa, latar, tema, dan amanat. Namun dalam naskah drama ini tidak di temukan indikasiindikasi yang menerangkan tentang unsur ruang. Berdasarkan hasil penelitian tentang struktur naskah drama Jaka Tarub dan 7 Bidadari karya akhudiat dapat di simpulkan sebagai berikut:

\section{A. Unsur tokoh, peran, dan karakter}

Tokoh yang terdapat dalam naskah drama ini terdiri dari sepuluh orang tokoh simbolis berdasarkan peran dan karakternya masing-masing. Tokoh, peran, serta karakter dalam naskah drama Jaka Tarub dan 7 Bidadari karya akhudiat dapat di lihat sebagai berikut:

Jaka Tarub, merupakan tokoh utama dalam naskah drama ini dan sosok Jaka Tarub ini di gambarkan ia begitu percaya dengan hal mistis, senang berburu, sopan, taat pada orang tua, bersahabat, licik, dan ingkar janji. Dan salah satu dialog yang menunjukan bahwa sosok seorang Jaka Tarub ini taat pada orang tua, yang membantu pekerjaan ibu nya tersebut.

Jaka Tarub: "Kalau begitu biar saya saja yang menyelesaikan pekerjaan Ibu hari ini"

Nawang Wulan, di dalam naskah drama ini sosok Nawang Wulan di gambarkan sebagai sosok seseorang bidadari yang baik hati, sosok seseorang wanita penyayang kepada anaknya, dan setia pada janji. Dan salah satu dialog yang menunjukan bahwa sosok Nawang Wulan ini penyayang kepada anaknya, di saat Nawang Wulan harus 
meninggalkan kedua anaknya, dan menyerahkan kedua anaknya kepada Jaka Tarub.

Nawang Wulan: "Jaga kedua anak kita, kang”

Ibu Jaka Tarub, di dalam naskah drama ini sosok Ibu Jaka tarub di gambarkan sebagai sosok seseorang ibu yang sangat peduli kepada anaknya. Dan salah satu dialog yang menunjukan bahwa sosok Ibu Jaka Tarub ini yang sangat peduli kepada anaknya untuk segera meminang sosok seorang wanita agar tidak sendiri lagi karena memang Jaka Tarub sudah dewasa, dan ibunya ingin segera menimsng cucu sebelum di panggil sang maha kuasa.

Ibu Jaka Tarub: "Nak, Ibu lihat kamu sudah dewasa, sudah pantas untuk meminang gadis. Lekaslah menikah, Ibu ingin menimang cucu sebelum Ibu pergi”

Raja Ajisaka, di dalam naskah drama ini sosok Raja Ajisaka di gambarkan sebagai sosok ayah yang sangat tegas, dan baik hati juga terhadap anak-anaknya. Dan salah satu dialog yang menunjukan bahwa sosok Raja Ajisaka seorang ayah yang sangat baik hati sekali menginzinkan anak-anaknya untuk pergi ke mayapada (Bumi) karena mereka rindu mandi di danau.

Raja Ajisaka: "Pergilah nak, tapi ingat pada saat terompet kerajaan berbunyi kalian semua harus segera kembali ke istana"

Ratu Sekar Dewi, di dalam naskah drama ini sosok Ratu Sekar Dewi di gambarkan sebagai sosok ibu yang sangat baik hati terhadap anakanaknya, dan juga sosok ibu yang lemah lembut. Dan salah satu dialog yang menunjukan bahwa sosok Ratu Sekar Dewi ini sangat lembah lembut terhadap anaknya yang lain padahal situasi saat itu sedang dalam keadaan yang panik dan cemas, salah satu anaknya tidak bisa kembali ke kahyangan dari mayapada (Bumi) karena selendangnya hilang entah kemana.

Ratu Sekar Dewi: "Kemana dia..? Kenapa kalian pulang tanpa adik kalian?" (menghampiri ke 6 bidadari dan bertanya dengan lembut).

Bidadari 1-6, di dalam naskah drama ini sosok Bidadari 1-6 di gambarkan sebagai sosok Bidadari yang ceria. Dan salah satu dialog yang menunjukan bahwa sosok Bidadari 6 ini sangat ceria sekali, karena akan pergi ke mayapada (Bumi) untuk mandi di danau.

Bidadari 6: “ wah rasanya bagai nusuk ke dada,, dinginnya akan 
meraba darahku. Wahhh... rasaya itu ????? "sambil menghayal”

Raja Bintara, di dalam naskah drama ini sosok Raja Bintara di gambarkan sebagai sosok raja yang jahat, segerombolan jin jahat pimpinan raja bintara yang sudah lama ingin mempersunting Nawang Wulan dan ke 6 kakaknya. Keinginan yang tentu saja ditolak mentahmentah oleh ke 7 bidadari maupun kedua orang tua mereka. Dan salah satu dialog yang menunjukan bahwa sosok Raja Bintara ini jahat adalah.

Raja Bintara: "Jangan salahkan aku jika terjadi sesuatu pada putri kalian" (menarik tangan Nawang Wulan).

Patih, di dalam naskah tersebut sosok patih ini adalah prajurit dari Raja Ajisaka, sosok patih ini di gambarkan tegas, dan salah satu dialog yang menunjukan ia bersosok tegas yaitu.

Patih : "Hamba setuju dengan perkataan Ratu Sekar Dewi, Raja.. Mungkin sudah takdir Nawang Wulan untuk tinggal di mayapada. Jadi kita tidak perlu melakukan apa-apa. Berharaplah semoga hal buruk tidak terjadi pada Nawang Wulan"

Laras dan Arya, di dalam naskah drama ini sosok Laras dan Arya adalah sosok manusia yang licik dan jahat dengan Nawang wulan dan Jaka Tarub, mereka berdua sangat licik karena berniatan akan menghancurkan pernikahan Nawang Wulan dan Jaka Tarub karena Laras mencintai Jaka Tarub dan Arya pun mencintai Nawang Wulan. Dan salah satu dialog yang menunjukan kelicikan dan kejahatan mereka adalah.

Laras: "Kita harus menghancurkan mereka"

Nawang Asih dan Jaka Tengil, di dalam naskah drama ini sosok Nawang Asih dan Jaka Tengil adalah anak yang baik hati, anak yang masih lugu dan belum banyak mengenal banyak hal. Ia adalah putri dan putra dari Jaka Tarub dan Nawang WulanDan di salah satu dialog ini, menjelaskan bahwa Nawang Asih dan Jaka Tengil tidak mau kehilangan sosok ibu yang sangat baik ini, Setelah Nawang Wulan mengetahui bahwa selendangnya dicuri oleh suaminya Jaka Tarub, Nawang Wulan pun memutuskan untuk kembali ke kahyangan dan meninggalkan Jaka Tarub dan kedua anaknya. Dialog tersebut adalah.

Nawang Asih : "Ibu, jangan tinggalkan Asih sendiri” (menangis sambil memeluk Ibunya) 
Jaka Tengil : "Iya bu, jangan tinggalkan kami sendiri”

Indra dan Banyu, di dalam naskah drama ini, sosok dari Indra dan Banyu ini penghasut, yang menghasut sahabat nya Jaka Tarub agar terusiklah rasa ingin tahu JakaTarub tentang Nawang Wulan karena hasutan Arya dan kedua teman Jaka Tarub yaitu Banyu dan Indra. Dan salah satu dialog yang menghasut Jaka Tarub adalah.

Indra : "Apa kamu tidak curiga kenapa beras di lumbung mu masih utuh, seolah-olah tidak pernah digunakan"

\section{B. Unsur Motif, Peristiwa, Konflik, dan Alur}

Konflik yang terjadi dalam naskah drama Jaka Tarub dan 7 Bidadari ini, adanya motif balas dendam antara Raja Bintara dengan Raja Ajisaka karena Penderitaan Nawang Wulan dan keluarganya adalah ketika kahyangan mereka di langit diserbu oleh segerombolan jin jahat pimpinan raja bintara yang sudah lama ingin mempersunting Nawang Wulan dan ke 6 kakaknya. Keinginan yang tentu saja ditolak mentah-mentah oleh ke 7 bidadari maupun kedua orang tua mereka. Sampai peperangan antara jin dan keluarga kerajaan pun tak dielakkan lagi. Berikut ini kutipan dialognya. pada kalian"

Raja Bintara : "Jangan paksa aku untuk melakukan kekerasan

\section{Unsur latar dan ruang}

Latar tempat yang dapat ditemukan dalam naskah drama Jaka Tarub dan 7 Bidadari adalah latar tempatnya adalah di desa terpencil, sawah, kahyangan, dan hutan. Adapun latar waktu terdiri dari hari ini, dan petang.

\section{Unsur penggunaan bahasa}

Unsur penggunaan bahasa yang di gunakan adalah bahasa yang mudah di mengerti dan di pahami oleh semua kalangan masyarakat, Dan alur yang pakai pun adalah alur maju. Drama Jaka Tarub dan 7 Bidadari karya akhudiat, di peroleh simpulan sebagai berikut: 1) Nakah Drama Jaka Tarub dan \& Bidadari memiliki empat belas tokoh simbolis beserta karakternya masing-masing. 2) Motif dalam naskah drama Jaka Tarub dan \& bidadari adalah hilangnya selendang Nawang Wulan salah satu bidadari dari kahyangan yang datang ke mayapada (Bumi) untuk mandi di danau bersama bidadari yang lainnya dan yang tak lain dan tak bukan Jaka Tarub sendiri lah yang menyembunyikan salah satu selendang bidadari itu secara diamdiam tanpa sepengetahuan siapa pun itu. 3) Peristiwa yang terjadi yaitu 
saat Jaka Tarub menyembunyikan selendang Nawang wulan dan Nawang Wulan pun pada akhirnya mengetahuinya jika suaminya lah yang menyembunyikan selendangnya tersebut, Nawang Wulan pun sangat kecewa sekali dengan kelakuan suaminya tersebut, pada akhirnya Nawang Wulan pun memutuskan untuk langsung kembali ke kahyangan dan meninggalkan kedua anaknya dan suaminya. 4) Konflik yang terjadi dalam naskah drama Jaka Tarub dan 7 Bidadari ini, yaitu adanya motif balas dendam antara Raja Bintara dengan Raja Ajisaka karena Penderitaan Nawang Wulan dan keluarganya adalah ketika kahyangan mereka di langit diserbu oleh segerombolan jin jahat pimpinan raja bintara yang sudah lama ingin mempersunting Nawang Wulan dan ke 6 kakaknya. Keinginan yang tentu saja ditolak mentah-mentah oleh ke 7 bidadari maupun kedua orang tua mereka. Sampai peperangan antara jin dan keluarga kerajaan pun tak dielakkan lagi. 5) Alur yang di gunakan adalah alur maju atau alur konvesional. 6) Latar tempat yang dapat ditemukan yaitu latar tempatnya adalah di desa terpencil, sawah, kahyangan, dan hutan. Adapun latar waktu terdiri dari hari ini, dan petang. 7) penggunaan bahasa yang di gunakan adalah bahasa yang mudah di mengerti dan di pahami oleh semua kalangan masyarakat. 8) Dan amanat yang bisa di ambil adalah, jangan merebut hak orang lain karena itu perbuatan yang tidak baik.

\section{DAFTAR PUSTAKA}

\section{Devi Soviana, Wika. 2019. Teori Sastra. Karanganyar: CV Al Chalief.}

Eryanti, W. N., Rahman, R., dan Permana, R. (2015). Analisis Struktur dan Nilai Moral dalam Kumpulan Naskah Drama "Kalangkang Urang" Karya Arthur S. Nalan. Dangiang Sunda 3(2), 1-7.

Nurgiyantoro, B. (1995). Teori Pengkajian Fiksi. Yogyakarta: Gajah Mada University Press.

Hasanuddin W. S. (1996). Drama Karya dalam Dua Dimensi Kajian Teori, Sejarah dan Analisis. Bandung: Angkasa. http://jim.stkip-pgrisumbar.ac.id/jurnal/download/7288

http://www.syekhnurjati.ac.id/jurnal/inde x.php/jeill/article/download/2175/1634

http://duniaevira.blogspot.com/2012/03/an alisis-struktur-naskah-dramamak.html 